\title{
Descentralización de la gestión del Patrimonio cultural: una mirada desde los municipios
}

\author{
Cultural Heritage Management decentralization: a view from local councils \\ Katherine San Martín Salgado* \\ Ignacio Abad Parraguez ${ }^{* *}$ \\ Samuel Aguilera Contreras ${ }^{* * *}$ \\ Francisco Navarrete Provoste ${ }^{* * * *}$
}

Resumen: La gestión patrimonial en Chile está viviendo uno de sus hitos más significativos a través de la creación de la Ley de Patrimonio Cultural, el cual viene a reconfigurar el abordaje y lógicas de trabajo que prevalecen actualmente. En este contexto, surge esta investigación que hace un recorrido por las normativas nacionales e internacionales que sustentan la gestión del Patrimonio Cultural y que, además, analiza los procesos actuales de declaratorias en Chile y las problemáticas que surgen a nivel local. Mediante entrevistas en profundidad a actores claves a nivel nacional y de América Latina, se dan a conocer sus visiones respecto al rol que deben cumplir los municipios en este ámbito, junto con las dificultades y los desafíos a los que se enfrentan. El artículo da a conocer la labor territorial de diversas ciudades latinoamericanas en la gestión patrimonial y la experiencia de la Unidad de Patrimonio de la Municipalidad de Chillán.

Palabras claves: Patrimonio cultural, municipios, gestión, América Latina, Chile, Chillán.

\begin{abstract}
The asset management in Chile is passing through one of its most meaningful landmarks thanks to the creation of Cultural Heritage Law, a landmark that comes to put together the approach and working styles that still thrive. In this context, this investigation comes up to make a review of the national and international regulations that support the management of Cultural Heritage, the current declaration processes in Chile, and the difficulties that emerge locally are analyzed. Through extensive interviews with national and Latin American key actors, their vision about the role that the local councils must accomplish in this area, the difficulties and the challenges they face are shown. The article states the territorial task of different Latin American cities on asset management and the experience of Unidad de Patrimonio, Chillán Municipality.
\end{abstract}

Keywords: Cultural Heritage, local council, management, Latin America, Chile, Chillán.

Recibido: 9 agosto 2020 Aceptado 5 octubre 2020

\footnotetext{
*Antropóloga Sociocultural, Universidad de Concepción, kathysanmartin.s@gmail.com

** Periodista, Universidad de Concepción, abad.parraguez@gmail.com

${ }^{* * *}$ Administrador Público, Universidad de Concepción, samuel.dac93@gmail.com

${ }^{* * * *}$ Administrador Público, Universidad de Concepción, navarretefrancisco9217@gmail.com
} 


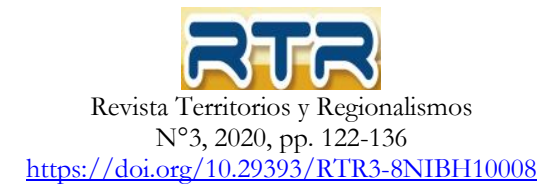

\section{Introducción}

La implementación de convenciones internacionales creadas en la Unesco, que estructuran el trabajo que se debe realizar a lo largo del país en el ámbito del patrimonio cultural, caracterizado por una diversidad cultural, compuesto por grupos heterogéneos con múltiples intereses y necesidades, nos invitan a reflexionar sobre las dificultades que este fenómeno conlleva en Chile y en América latina.

En el siguiente trabajo, se realizará un recorrido histórico por las normativas vigentes y abordaremos el proceso actual en el que se encuentra el proyecto de Ley de Patrimonio cultural, el que viene a modificar la lógica centralista con la que se patrimonializa y gestiona en el país. Por este motivo, se dará a conocer el rol de la gestión patrimonial desde las municipalidades, enfocándonos en la Unidad de Patrimonio de la Municipalidad de Chillán y en experiencias de países en América latina. Además, se identificarán las herramientas con las que cuentan, su visión sobre los procesos a los que se enfrentan, como también los desafíos que se identifican para mejorar el trabajo que se realiza a nivel local junto a las comunidades.

La metodología utilizada en este estudio es de tipo cualitativo con un carácter exploratorio y descriptivo, utilizando como herramienta de levantamiento de información cuatro entrevistas semiestructuradas, aplicada a cinco actores clave en la gestión del Patrimonio cultural a nivel local, nacional y en América latina.

\section{Normativa relacionada al patrimonio cultural}

Antes de comenzar con un análisis minucioso y detallado sobre el proceso de descentralización en la gestión del patrimonio cultural, es menester ofrecer una definición de este concepto y sus ramificaciones.

El patrimonio cultural, según la Organización de las Naciones Unidas para la Educación, la Ciencia y la Cultura (Unesco), se entiende como el legado recibido del pasado, que se vive en el presente y que se transmite a futuras generaciones. Es una señal de identidad que favorece la cohesión de las comunidades. El patrimonio cultural se divide en dos tipos, ya que uno comprende colecciones de objetos, infraestructuras y monumentos, y el otro contempla los saberes, técnicas o expresiones vivas que han sido heredadas por antepasados. Esta separación es conceptualizada como patrimonio cultural material y patrimonio cultural inmaterial.

En ese sentido, las actividades y estrategias para salvaguardar y poner el valor el patrimonio cultural ayuda a favorecer la creatividad y el bienestar social de comunidades, y contribuyen a una mejor gestión en los territorios.

\section{Una necesaria intervención de la Unesco}

Con el objetivo de garantizar la identificación, protección y la conservación adecuada del patrimonio a nivel mundial, la Unesco aprobó -el 21 de noviembre de 1972- la Convención del Patrimonio Mundial. Este tratado comprometió a los Estados que los suscribieron a conservar, rehabilitar, proteger y transmitir el patrimonio cultural y natural de sus respectivos territorios. Conjuntamente, el instrumento ofrece un sistema de asistencia y cooperación internacional para apoyar los esfuerzos que ejecuta cada país para identificar y preservar el patrimonio.

Este acuerdo se concretó después que se previera el deterioro o desaparición del patrimonio en varios pueblos del mundo, debido a la amplitud y gravedad de los nuevos peligros que amenazaban a los 


\section{RT? \\ Revista Territorios y Regionalismos \\ $N^{\circ} 3,2020$, pp. 122-136 \\ https://doi.org/10.29393/RTR3-8NIBH10008}

diferentes Estados. También se tomó en cuenta la poca voluntad protección y de recursos que existía en algunas naciones para asegurar el total cuidado y salvaguardia de bienes del patrimonio cultural y nacional. Por eso se consideraba trascendental la creación de un instrumento normativo que asegurara la protección del legado de la humanidad (Unesco, 1972).

Ya oficializado este documento, cada Estado Parte se comprometió a asignar recursos para cumplir con la labor de identificación, rehabilitación, conservación y protección del patrimonio. Y para cumplir con lo mencionado, se creó un Comité del Patrimonio Mundial para hacer valer los acuerdos mencionados, junto con estudiar las propuestas de asistencia internacional y analizar las solicitudes que levantan diversos países para que sus manifestaciones de patrimonio sean oficializadas como sitios del patrimonio mundial. Pese a que el tratado fue promulgado en noviembre de 1972, Chile aprobó su adhesión en enero de 1980 y oficializó su incorporación el 27 de marzo del mismo año. En Chile hay seis sitios declarados como patrimonio mundial: Qhapac Nan, Ciudad minera de Sewell, Rapa Nui, Centro histórico de Valparaíso, Oficinas Salitreras de Humberstone y Santa Laura e Iglesias de Chiloé.

\section{Ley de Monumentos Nacionales}

La primera normativa sobre monumentos nacionales se promulgó en 1925, en pleno periodo de crisis política e institucional, a 17 días de la renuncia de Arturo Alessandri Palma. Fue en octubre de ese convulsionado año en que se promulgó el Decreto Ley Nº51 del Ministerio de Instrucción Pública, que legisló sobre los monumentos del país y, además, constituyó el Consejo de Monumentos Nacionales. Este decreto también estableció las categorías del patrimonio que estarían bajo protección del Estado y fijó restricciones y sanciones para garantizar su protección.

Con el pasar de los años, se hizo evidente la necesidad de una actualización del marco legal chileno en la materia. Por esta razón, en 1970, durante el Gobierno de Eduardo Frei Montalva, se procedió a la derogación del Decreto Ley No 651 y se promulgó la Ley Nº17.288 de Monumentos Nacionales, que está vigente hasta hoy.

Y pese a que no ofreció un cambio radical en relación al decreto anterior, esta ley se estableció como una mejor herramienta en materia de protección del patrimonio en Chile, especialmente en los nuevos atributos que le otorgó al Consejo de Monumentos Nacionales para su funcionamiento (Historia de la Ley $\left.\mathrm{N}^{\circ} 17.288,1970\right)$.

Para ejemplificar lo anterior, se puede consignar el aumento de los miembros del Consejo, junto con la incorporación de expertos de otras disciplinas y oficios. Esta modificación le dio un mayor presupuesto a la entidad. En esa misma línea, también aumentaron las multas por las infracciones que se cometieran contra los monumentos protegidos.

Otra particularidad de esta ley tiene relación con la conservación de caracteres ambientales, la valoración del contexto urbano y el realce que se le otorgó no sólo los grandes edificios o palacios, sino que también barrios obreros, industriales, portuarios. Según esta ley, cada uno de estos conjuntos no sólo serían valiosos por su diseño o materiales de construcción, sino que también se considerarían el uso que le dieron sus habitantes. La ley declara las siguientes categorías: Monumento Histórico, zona típica, monumento público, monumento arqueológico y santuario de la naturaleza

No obstante, tal como se abordará en extenso en este trabajo, el pasar del tiempo ha planteado nuevos desafíos. $\mathrm{Y}$ aunque se han realizado algunas pequeñas modificaciones de orden institucional -como la creación Ministerio de las Culturas, las Artes y el Patrimonio, que pasó a comandar las acciones del 


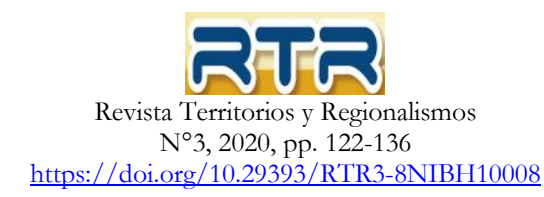

Consejo de Monumentos Nacionales (que antes dependía del Ministerio de Educación- muchos investigadores y especialistas en la materia sostienen que la ley vigente no responde a las necesidades presentes del patrimonio cultural en el país.

\section{Una nueva fuerza para el patrimonio cultural inmaterial}

El 17 de octubre de 2003, la Asamblea General de la Unesco aprobó la Convención para la Salvaguardia del Patrimonio Inmaterial. Este nuevo acuerdo permitió establecer un marco normativo -con estándares actualizados- para responder a las necesidades de reconocimiento, valoración y fortalecimientos de los distintos elementos culturales que están presentes en el patrimonio cultural inmaterial. Este tipo de patrimonio cultural es sumamente relevante, pues considera y les otorga realce a diversas prácticas, como las tradiciones orales, música, danza, artes del espectáculo, rituales, modos de vida, medicina tradicional, festividades, ceremonias religiosas, saberes y técnicas de artesanía tradicional, y prácticas relativas a la naturaleza y el universo.

Este nuevo instrumento sirvió para complementar los otros tratados internacionales relacionados. Además, su redacción y definición le permitió ser coincidente con declaraciones y convenciones aprobadas en los años siguientes por la ONU y la misma Unesco.

Chile suscribió a la Convención para la Salvaguardia del Patrimonio Inmaterial en 2008 y el encargado de su implementación es el Ministerio de las Culturas, las Artes y el Patrimonio a través del proceso para la salvaguardia, el que busca otorgar las condiciones y la viabilidad en el tiempo de los elementos reconocidos en el Registro e Inventario del PCI en Chile.

\section{Patrimonialización en Chile, un proceso centralista}

Para abordar el proceso de patrimonialización en Chile, nos enfocaremos en los dos ejes centrales que permiten gestionar el patrimonio cultural desde una mirada institucional, es decir, desde lo material e inmaterial. Si bien la separación de estos dos ámbitos es necesaria para establecer una relación entre el Estado y la ciudadanía, y así desarrollar un trabajo específico para cada una de las necesidades técnicas que se requieren, el patrimonio cultural debe ser entendido desde una concepción integral, inherente al ser humano y a su cultura. Para García Canclini (2005) "el patrimonio, ya sea material o inmaterial se construye como un símbolo duradero, que permite a un pueblo o grupo, hablar sobre su pasado y, especialmente, sobre su presente; convirtiéndose en un marcador de identidad" (p. 186).

Actualmente, el Servicio Nacional del Patrimonio Cultural es el organismo encargado de gestionar el reconocimiento, el resguardo y el acceso al patrimonio de forma participativa y contribuir a mejorar la calidad de vida de las personas. Es en esta institución donde recae la responsabilidad de generar los procesos de reconocimientos y declaratorias del patrimonio presente en el país, bajo el amparo de la normativa nacional e internacional relacionada con cada uno de los ámbitos recién mencionados, los que buscan una participación de la ciudadanía que solicita dichas declaratorias desde los territorios, pero la decisión de qué es declarado o reconocido como patrimonio cultural en Chile es tomada por técnicos que responden a una visión centralista, alejada de los territorios solicitantes. Si bien este modelo intenta que las comunidades definan cuál es el patrimonio cultural de sus localidades a través de los expedientes que respaldan una solicitud, dando a conocer la valoración social, histórica y vínculo que existe a nivel territorial, estos argumentos deben ser comprendidos por los integrantes del comité asesor del Patrimonio cultural inmaterial o Consejo de Monumentos Nacionales (en el caso del patrimonio material) quienes revisan las postulaciones basándose en los criterios establecidos por Unesco a través de la Convención para la Salvaguardia del Patrimonio Cultural Inmaterial del año 2003 o mediante lo señalado en la Ley de 


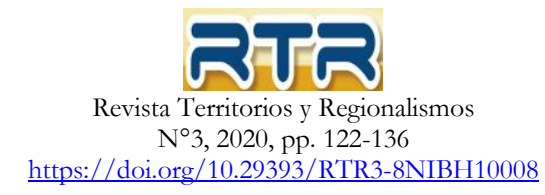

Monumentos Nacionales. Sin embargo, una declaratoria está sujeta a la comprensión de la postulación, el conocimiento anterior por parte del experto, la discusión que se desarrolla en el momento de decidir y las presiones políticas o mediáticas que existen a la hora patrimonializar; factores determinantes que pueden afectar a una comunidad que necesita iniciar un proceso de salvaguardia o protección de su patrimonio cultural por parte del Estado.

El proceso de patrimonialización en Chile, responde a una lógica centralista basada en los conocimientos de expertos que deben decidir cuál es el patrimonio cultural que reconoce el país, considerando los argumentos que entregan las comunidades solicitante a través de procesos complejos que requieren el manejo de un lenguaje técnico vinculado a las ciencias sociales o arquitectura, lo que obstaculiza el procedimiento y la relación que existe entre la ciudadanía interesada en preservar sus bienes culturales y el Estado a cargo de esa función. Zamora, hace referencia a este fenómeno de la siguiente manera:

El patrimonio es dinámico, y su construcción y conservación (y también su destrucción) responde a variables que no dependen de la opinión de los expertos sino de las características estructurales y de las trayectorias históricas de las sociedades (o de cada uno de los grupos que las componen) constituidas en sujetos de su propia historia. En un elemento dinámico que se construye y reconstruye permanentemente (Zamora, 2011, p.107).

Este mecanismo coarta las posibilidades que tienen los habitantes en las diferentes regiones para determinar una gestión efectiva y representativa, requisitos fundamentales para proteger el patrimonio cultural a través de acciones que apunten a la sustentabilidad, ya que, si no existe una apropiación local de las declaratorias, los recursos humanos y económicos destinados para la salvaguardia no serán efectivos.

\section{Necesidad de una gestión del patrimonio cultural desde los municipios}

Hablar de patrimonio cultural desde lo local y desde los municipios, es de suma relevancia cuando nos encontramos frente a un proyecto de Ley de Patrimonio Cultural, el que busca actualizar la ley $\mathrm{N}^{\circ} 17.288$ de Monumentos Nacionales, que data de 1970 y a la vez consolida una normativa establecida en 1925, la que no ha tenido modificaciones. Este proyecto surge frente a la necesidad de actualizar las categorías actuales a través de una visión integral y otorgar una protección efectiva al patrimonio cultural presente en Chile mediante la identificación, conservación, puesta en valor, gestión y promoción. Una de las líneas que este proyecto de ley busca abordar -ya que es identificado como una problemática latente en el países el centralismo del órgano colegiado a cargo de la patrimonialización, es por ello que se busca una regionalización en la toma de decisiones, además de una protección efectiva y eficaz.

"Necesitamos un cambio de ley que permita desatomizar la toma de decisiones mediante consejos regionales, para fortalecer la gestión local y así tener un cambio de paradigma que apunte a la descentralización" (Erwin Brevis, Secretario Técnico CMN).

En una senda similar, Javier Ramírez, quien es el encargado de la Unidad de Patrimonio de la Universidad de Concepción menciona la necesidad de mejorar los procesos de gestión apuntando a la descentralización.

La protección a un monumento y su declaratoria, debiese hacerse a nivel local por el conocimiento que se tiene, por un tema de gestión y de mejora de los procesos de gestión. Sin embargo, creo que hablar de una administración local, cuando no existe una estructura descentralizada en chile, es muy difícil de abordar porque se habla 


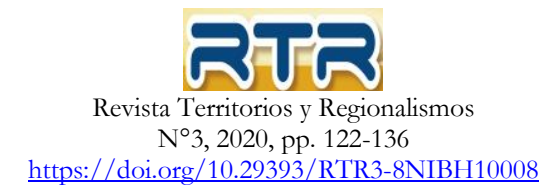

sobre algo que no existe (Javier Ramírez, encargado de la unidad de patrimonio de la Universidad de Concepción).

En atención a esta coyuntura, surge el interés por ahondar sobre la gestión del patrimonio cultural con una mirada local, enfocándonos en el rol que cumplen los municipios en dicho ámbito y los posibles desafíos. Según lo señalado por Adriana Molano, directora del Centro Regional para la Salvaguardia del Patrimonio Cultural Inmaterial de América Latina (CRESPIAL) “(...) es una oportunidad inmensa para generar desarrollo local desde la identidad, puesto que tiene muchos beneficios para aquellos municipios que tengan la capacidad de elaborar una planificación que apueste a la cultura".

Implementar políticas públicas de patrimonio cultural que responden a estructuras internacionales y normativas nacionales, tienen una serie de dificultades al momento de su ejecución, ya que deben enfrentarse a la diversidad sociocultural existente en los distintos territorios, con las complejidades, estructuras y símbolos que cada uno de ellos tiene, y en los que comunidades debiesen decidir sobre el devenir de sus acervos. Desde el modelo institucional actual y centralista, se dificulta la lectura de las colectividades y la gestión horizontal que requiere este ámbito para una salvaguardia que trascienda generaciones, por lo que cobra relevancia el rol de las municipalidades.

"Los municipios generan un impacto directo en la gente, son ellos quienes están ahí en el roce, en la fricción, si tú generas impacto a través de los municipios, transformas Chile" (Erwin Brevis, Secretario Técnico CMN) .

La Municipalidad es la primera institución a la que acuden los ciudadanos/as para resolver sus problemáticas y recibir orientación, es por eso que para avanzar en la gestión del patrimonio cultural lo más cercana a la realidad local, es importante que estas instituciones conozcan el rol que ellos cumplen como actores claves en la protección y salvaguardia, entiendan las normativas nacionales e internacionales para poder informar de forma correcta, pero a la vez sean quienes lideren los procesos de declaratoria, protección, salvaguardia y valoración del patrimonio en la comuna a través de las herramientas y potestades con las que cuentan. La articulación intersectorial a la que se puede acceder desde un municipio, facilita y potencia las posibilidades de acción y eficacia con la que se puede desarrollar un trabajo a largo plazo que asegure la representatividad y apropiación de las medidas por parte de las comunidades legatarias y portadoras del patrimonio.

La Convención para la Salvaguardia del Patrimonio inmaterial de la Unesco, plantea muy claramente que quien identifica y gestiona el patrimonio son las comunidades, pero no siempre tienen esas capacidades, no siempre tienen esas necesidades, no siempre tienen esas competencias, entonces quien debería estar más cerca de ellos es el nivel municipal, ellos deberían generar esas capacidades, pero desde el rol de facilitador y en un ideal de corresponsabilidad (Adriana Molano, directora CRESPIAL).

Entender el ámbito cultural y patrimonial como un eje de trabajo en una administración municipal, es una herramienta que abre posibilidades a través de las cuales se pueden activar las economías locales, potenciar las identidades, activar las memorias colectivas y propender a que los grupos portadores de saberes tradicionales cuenten con las condiciones que les permitan seguir transmitiendo sus conocimientos a las nuevas generaciones, así lo señala la encargada de la Unidad de Patrimonio de la Municipalidad de Chillán 


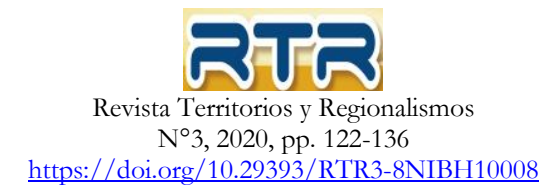

"Finalmente, todo tiene que ver con un modelo de desarrollo económico y social, el que ya no favorece a las relaciones humanas, así es muy difícil transmitir en el día a día las historias de los barrios, de los niños, de sus antepasados”. (Karin Cárdenas, encargada UPA Chillán)

Una de las tensiones a las que se enfrenta constantemente el patrimonio cultural material e inmaterial, tiene relación directa con la visión de desarrollo predominante, el que según Arturo Escobar tiene las siguientes características:

El desarrollo era, y sigue siendo en gran parte, un enfoque de arriba hacia abajo, etnocéntrico y tecnocrático que trata a la gente y a las culturas como conceptos abstractos, como cifras estadísticas que se podían mover de un lado a otro en las gráficas del progreso. (Escobar, 1997, p.86).

En la misma línea, los autores Perafán y Pabón (1998) indican que el desarrollo es solo una continuación de la idea de progreso, dentro de un contexto globalizador y en el cual intervienen constantemente organismos nacionales e internacionales.

Estas definiciones nos introducen a unas de las problemáticas que ponen en tensión la gestión del patrimonio cultural frente a los intereses institucionales y de mercado que afectan a los territorios. Los contextos comunitarios y barriales se ven afectados por la intervención inmobiliarias, edificaciones, construcción de carreteras, presencia de forestales, chancadoras y la pérdida de sus materias primas; acciones que vienen a cambiar las dinámicas cotidianas e impiden la viabilidad en el tiempo de los patrimonios culturales. Actualmente, solucionarlos depende de una acción centralista, sin embargo, si las municipalidades tuviesen las potestades y los conocimientos técnicos para abordar estas problemáticas del patrimonio cultural y además fuese una prioridad dentro de su gestión, se podrían evitar esas pérdidas y conflictos que nos llevan a repensar el lugar que habitamos, comprendiendo el dolor de quienes lo habitan y son obligados a desprenderse de lo que los conecta con su memoria y antepasados. Es en estos momentos de conflicto cuando las administraciones locales adquieren un rol preponderante, al conocer las configuraciones del entramado social y tener un diálogo directo con las comunidades, características que facilitan la toma decisiones en el ámbito patrimonial.

Seguimos gobernando desde el escritorio, conocer el país de verdad es un gran desafío, confiar que los gobiernos locales sí conocen el territorio y entonces desde ahí se puede articular el gobierno nacional que conoce las normas, conoce todo este tema en términos internacionales, pero no confían en las capacidades de lo local, pero lo local conoce el territorio y lo nacional no logra llegar ahí (Adriana Molano, directora CRESPIAL).

\section{Experiencia Unidad de Patrimonio Municipalidad de Chillán}

En lo que respecta a la gestión patrimonial de los municipios, cabe decir que no existe un precepto legal que obliga a desarrollar unidades de patrimonio en estos organismos, por lo que cada municipio decidirá de forma autónoma como llevará a cabo la gestión patrimonial. En el caso de la municipalidad de Chillán, ya desde el año 2013 que viene trabajando con su unidad de patrimonio, con el fin de reforzar y proteger la identidad local, buscando que la ciudadanía se involucre en los diferentes procesos.

\section{Posicionamiento del patrimonio cultural de la Municipalidad de Chillán}




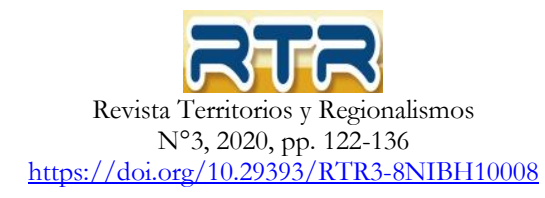

Para Karin Cárdenas -encargada de la unidad de patrimonio de la Municipalidad de Chillán- la principal dificultad para insertar el patrimonio cultural dentro de la gestión municipal está relacionada con la conciencia que se pueda tener de que el patrimonio y la identidad son importantes para el desarrollo local. Para esto, es importante tener una estrategia de comunicación entre los funcionarios involucrados en patrimonio y las autoridades políticas de la comuna, ya que de esta forma se puede posicionar de manera efectiva el desarrollo del patrimonio a nivel local. Sin embargo, esto dependerá de la realidad de cada administración comunal, ya que no todos tienen el mismo enfoque o importancia de lo que deben realizar en lo que respecta a los procesos de patrimonialización.

En el caso de la Municipalidad de Chillán, la estrategia para posicionar el patrimonio cultural en la agenda local y en la ciudadanía, se basa en una primera instancia en la educación, ya que si no existe el conocimiento adecuado se vuelve complicado valorar la cultura de la localidad. Es por esto que es imprescindible "la necesidad de un seguimiento y medición constantes de la educación patrimonial en aras a lograr programas educativos sólidos, sustentados sobre principios psicopedagógicos, capaces de objetivar y, en consecuencia, medir las acciones en materia de educación patrimonial que se generan" (Fontal, 2016, p.430).

Cuando se logre esto, vendría lo que la encargada denomina como "activar" y "que tiene que ver con el proceso de patrimonialización, donde se identifican "valores asociados a mi identidad y que quiero como preservar para futuras generaciones" (Karin Cárdenas, encargada UPA Chillán). Esto quiere decir que luego de adquirir el conocimiento del patrimonio cultural de cada localidad, luego se determina qué valores predominarán en el tiempo. Finalmente, luego de esta concientización, viene la protección donde se vela por la salvaguardia de la identidad local y territorial, para que los valores comunes se sigan manteniendo a lo largo de las generaciones. Por lo tanto, la estrategia para involucrar a la ciudadanía en la gestión del patrimonio cultural, se debe tener siempre en cuenta los tres verbos utilizados por la unidad de patrimonio de la Municipalidad de Chillán, que serían: Educar, Activar y Proteger.

\section{Rol del patrimonio a nivel local}

Karin Cárdenas (encargada UPA Chillán), menciona además que, dentro de los beneficios de una buena gestión municipal, el patrimonio cumpliría una función de sensibilizar a los ciudadanos que habitan en determinados territorios y de esta forma se fomentaría el fortalecimiento de las identidades locales. De esta forma se agrega un componente emotivo y de bienestar a las personas que comparten una cultura y tradiciones en común, por lo que una buena gestión patrimonial ayudaría a crear y/o fortalecer el sentido de pertenencia, lo que contribuye a tener una ciudadanía más empoderada con las decisiones que se puedan tomar a nivel territorial. Es por esto que la gestión debe considerar la participación de los habitantes de la comuna de Chillán, de esta forma se mantendrá en el tiempo la idea colectiva de proteger el patrimonio. O explicado de otra forma, "Las comunidades más organizadas luchan para evitar la desintegración de su tejido social y lograr la preservación de los espacios significativos para la memoria colectiva; las menos organizadas sufren la desintegración y pérdida del patrimonio cultural" (Santa-Cruz, 2018, p.266).

Sin embargo, la mayor dificultad para lograr lo mencionado tiene que ver con los recursos que asigna el municipio a lo realizado por la gestión patrimonial y/o cultural, ya que por parte de la unidad de patrimonio se exige una mayor cantidad de especialistas en determinadas áreas para generar un mayor impacto en la ciudadanía. Y para poder lograr esto se necesita voluntad política. Así lo explica la encargada de la unidad de patrimonio, refiriéndose a los cambios presupuestarios de la municipalidad:

"Entonces la gestión es compleja por el tema de los recursos. Requiere de muchos recursos siempre, requiere de la voluntad política y eso es como complejo. Por ejemplo, en nuestro municipio nos ha costado un montón también como poder 


\section{分的 \\ Revista Territorios y Regionalismos \\ $\mathrm{N}^{\circ} 3,2020$, pp. 122-136 \\ https://doi.org/10.29393/RTR3-8NIBH10008}

crecer en cuanto a presupuesto, porque se sigue creyendo que el patrimonio solamente es como difundir o recordar el pasado o escribir libros, pero cuando se negocia para invertir dinero en presupuesto, en recuperar ciertos inmuebles que están deteriorados, hasta ahí llega la conversación porque estamos hablando de miles de millones" (Karin Cárdenas, Encargada UPA Chillán).

Por lo tanto, si no existe una capacidad de negociación en defensa de la gestión patrimonial, es posible que no exista una redistribución adecuada para cumplir con los objetivos propuestos por la UPA.

No obstante, a partir de la creación de la región de Nuble, estas dificultades se han ido disminuyendo, dado que la gestión de recursos se centralizó administrativamente en Chillán y los diálogos con los funcionarios responsables ha sido de manera más directa y más efectiva.

Por lo que se puede decir que, al tener la nueva región, también existe otro entendimiento respecto a las necesidades e identidades territoriales y por lo tanto mayor facilidad para obtener recursos ya que existe una mayor comprensión de lo que sucede a nivel local.

Dicho esto, esta descentralización a nivel regional, favorecería a las municipalidades de Nuble, ya que se facilitaría la sensibilización y la participación ciudadana de los habitantes del territorio al tener unas costumbres e identidades comunes, y que ahora es administrada con mayor legitimidad. Por este motivo en el proceso de patrimonialización habrá más certeza de lo que querrán las distintas comunidades respecto a los valores que quieren salvaguardar y de esta forma habrá una respuesta más eficiente por parte de los organismos públicos de la nueva región, dado que ahora tendrán mayor autonomía. De esta manera se puede decir que la regionalización favorece a las municipalidades, dado que existe una mayor facilidad comunicacional con el nuevo Gobierno Regional.

Por consiguiente, el proceso de patrimonialización debe considerar la participación ciudadana y la gobernanza. Caso contrario si fuese impuesto por una autoridad, no tendría legitimidad ante la ciudadanía y por lo tanto debe ser un trabajo en conjunto con los organismos públicos, pues el rol que cumple la Municipalidad de Chillán es de concientizar a la ciudadanía para que puedan tomar decisiones respecto al patrimonio de la ciudad. De esta forma lo explica Karin Cárdenas:

Lo más importante, creo que es que la ciudadanía tome conciencia, que lo vea como una causa importante a discutir, a poner en la mesa y que meta ruido siempre. Eso es lo más importante, porque finalmente, para que las autoridades despierten y pongan atención a que este tema es importante. Es un tema ciudad... Pero siempre creo yo que lo más importante es tener una comunidad empoderada, súper clara de cuál es su patrimonio y la defensa que llevan". (Karin Cárdenas, Encargada UPA Chillán).

Por esta razón, es que una buena gestión del patrimonio cultural contribuiría al desarrollo local, dado que al tener claro cuál es el sentido de pertenencia del territorio, se hará más practico crear políticas públicas con un enfoque cultural y local, lo que favorecería al bienestar de la comunidad. De este modo hay que considerar que todas las municipalidades tendrán enfoques diferentes, ya que en cada localidad tendrán historias, valores y costumbres distintas y por consiguiente estas administraciones locales tendrán que tener en cuenta estas particularidades a la hora de llevar a cabo los procesos de patrimonialización. La democratización de los espacios y la discusión ciudadana son importantes para orientar el desarrollo comunal basado en intereses comunes.

\section{Proyecciones para la Municipalidad de Chillán}

Para Karin Cárdenas (encargada UPA Chillán), la nueva ley de patrimonio sería un avance para tomar mayores decisiones a nivel local, dado que las solicitudes de declaratorias o la solicitud de permisos para 


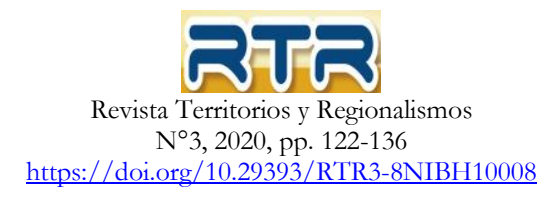

hacer intervenciones se tendrían que ver con las nuevas oficinas regionales encargadas. Sin embargo, esta ley no ha podido ser promulgada, ya que varios actores políticos se encuentran en pugna debido a la transferencia de competencia que debiesen tener las diferentes comunidades, "lo que produce inestabilidad e incertidumbre en la aplicación del nuevo diseño institucional para la administración del territorio" (Valenzuela y Henríquez, 2019, p.165). Ante esta disputa de diversos actores por una ley de patrimonio, a la municipalidad solo le queda por enfocarse dentro de las competencias propias que tiene, y por lo tanto continuar con la orientación de educar a los ciudadanos, sobre todo a los niños y niñas, para que sean ellos quienes sigan protegiendo y proyectando el patrimonio de la comunidad a lo largo del tiempo.

Por último, buscar la forma de hacer partícipe a la ciudadanía, para que los procesos tengan mayor legitimidad y por consecuencia exista un mayor interés político al llevar los intereses de las personas a la gestión del municipio. $\mathrm{O}$, dicho de otra forma:

La participación ciudadana en la gestión municipal no depende únicamente de mayores transferencias provistas por los niveles centrales de gobierno o de incentivos externos a nivel municipal, sino que también está relacionada con un cambio cualitativo en la forma de hacer gestión en el espacio local. Cuando este cambio se produce desde ese nivel, pueden lograrse iniciativas profundas de participación ciudadana" (Montecinos, 2006, p.191).

En razón de ello, es que dada la autonomía que tienen las municipalidades, estas pueden involucrar a las comunidades de la localidad en cuestión, para ir realizando cambios a la forma de gestionar el patrimonio en la comuna, sin la necesidad de tener que esperar la promulgación de la ley de patrimonio. Cuando entré en vigencia sin duda beneficiará a la descentralización, pero la participación ciudadana es esencial para llevar a cabo los objetivos patrimoniales y culturales de la comuna de Chillán.

\section{Experiencias latinoamericanas de gestión local del patrimonio cultural}

La gestión local del patrimonio cultural a nivel latinoamericano ha sido parte del desarrollo de comunas, distritos o cantones, que mediante una normativa adecuada ha permitido poner en valor este ámbito. Revisaremos los casos de gobiernos locales y universitarios de Perú, México y Ecuador en la gestión de sus Sitios de Patrimonio Mundial según la Unesco: Ciudad de Cusco y Centro Histórico de Lima, Campus Universitario de la UNAM y Santa Ana de los Ríos de Cuenca:

\section{a) Municipalidades de Cusco y Lima (Perú)}

En la ley orgánica de municipalidades peruana, ley nº 27972 del 2003, establece competencias y funciones específicas compartidas con el nivel nacional, respecto a la gestión del patrimonio cultural en:

- Promoción del Patrimonio Cultural: Promover la protección y difusión del patrimonio cultural de la nación, dentro de su jurisdicción, y la defensa y conservación de los monumentos arqueológicos, históricos y artísticos, colaborando con los organismos regionales y nacionales competentes para su identificación, registro, control, conservación y restauración (art. 82).

- Coordinación con Nivel Nacional: Las municipalidades provinciales, en coordinación con el Instituto Nacional de Cultura o a su solicitud, pueden establecer limitaciones especiales por la necesidad de conservación de zonas monumentales y de edificios declarados monumentos históricos o artísticos, de conformidad con las leyes sobre la materia y con las ordenanzas sobre protección urbana y del patrimonio cultural. (art. 82) 


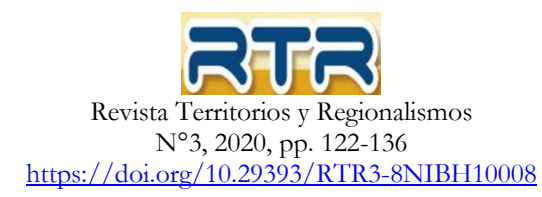

- Conservación de Patrimonio Cultural Material: Las municipalidades provinciales, en coordinación con el Instituto Nacional de Cultura o a su solicitud, pueden establecer limitaciones especiales por la necesidad de conservación de zonas monumentales y de edificios declarados monumentos históricos o artísticos, de conformidad con las leyes sobre la materia y con las ordenanzas sobre protección urbana y del patrimonio cultural (art. 91).

-Necesidad Pública: La salvaguarda, restauración y conservación de inmuebles incorporados al patrimonio cultural de la Nación o de la humanidad o que tengan un extraordinario valor arquitectónico, artístico, histórico o técnico, debidamente declarado como tal por el Instituto Nacional de Cultura.

\section{Programa Municipal para la recuperación del centro histórico de Lima - PROLIMA $^{1}$}

En el caso de la Municipalidad de Lima tiene en su aparato administrativo un órgano Administrativo PROLIMA que tiene como finalidad "Órgano desconcentrado de la Municipalidad de Lima que tiene como finalidad "promover la recuperación del Centro Histórico de Lima declarado Patrimonio Cultural de la Nación e inscrito en la lista del Patrimonio Mundial de la Unesco” y ejecuta el Plan Maestro del Centro Histórico de Lima. El Plan Maestro del Centro Histórico de Lima 2019-2029 (con visión al 2035) tiene tres ejes estratégicos que representan la visión de ciudad que tiene este plan.

Eje estratégico: El Centro de Lima como paisaje histórico cultural que realza los valores excepcionales del patrimonio de Lima.

Eje estratégico II: El Centro de Lima como centro vivo y lugar atractivo para residir e invertir.

Eje estratégico III: La zona monumental de Lima como centro metropolitano de carácter tradicional, cultural y turístico, integrado a la ciudad.

Hay desafíos institucionales, la mirada de la gestión por ejemplo en la Municipalidad de Lima, nosotros implementamos este plan de salvaguardia de patrimonio inmaterial pero antes de nosotros en los procesos de trabajo, se limitaban a un concurso sobre un baile típico o concursos de oratoria relacionados a una expresión cultural. Lo otro es generar los espacios de participación real con las personas con las que se trabaja, que no se manejen solamente en el ámbito técnico (Gabriela Ugarte, Técnico Crespial).

\section{Gerencia del Centro Histórico de la Municipalidad Provincial de Cusco ${ }^{2}$}

En 2009, según Bonet (p.4) una de las problemáticas sociales de la ciudad de Cusco era la pérdida progresiva del patrimonio cultural inmaterial al existir despoblamiento, pobreza urbana, débil representación y participación ciudadana y la falta integración de los cusqueños provocando indiferencia en el patrimonio cultural. Este problema es uno de los ejes del Plan Maestro del Centro Histórico del Cusco que involucra plenamente al Municipio Provincial.

La respuesta del Estado en gestión del patrimonio cultural material en la Municipalidad Provincial de Cusco para conservar la "Ciudad de Cusco", su lugar de Patrimonio de la humanidad tiene bajo su alero la Gerencia del Centro Histórico que es un órgano cuya función es la:

Gestión y conservación del Centro Histórico y de las Áreas Históricas de la ciudad del Cusco, así como la formulación e implementación de planes y proyectos específicos en función de las actividades productivas y sociales, de acuerdo a las

\footnotetext{
${ }^{1}$ http://www.munlima.gob.pe/programa-municipal-para-la-recuperacion-del-centro-historico-de-lima

2 https://cusco.gob.pe/gerencia-del-centro-historico/
} 


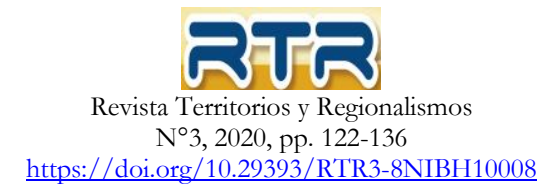

políticas de desarrollo municipal, conservación del patrimonio cultural y natural, en armonía con las normas locales, nacionales e internacionales vigentes

La técnico en Patrimonio Cultural Inmaterial de CRESPIAL, centro con sede en Cusco, señala que "Las fortalezas del Estado peruano ha sido instalar este sistema de declaratorias a nivel nacional en el que han desarrollado una estrategia en el campo de la gestión y salvaguardia del PCI, mediante las declaratorias nacionales y las de reconocimiento" (Gabriela Ugarte, Técnico Crespial)

\section{b) Universidad Autonoma de Mexico3(UNAM)}

El Campus de la Ciudad Universitaria entró a la lista de Sitios de Patrimonio de la Humanidad en el 2007 y la UNAM ha elaborado un plan de gestión de su patrimonio cultural para salvaguardar su calidad, valores y atributos materiales, preservar la integridad y la morfología que le caracterizan para las generaciones futuras y promover su vigencia y constante actualización del sitio, en respuesta a las necesidades de la comunidad universitaria. Este plan pretende ser un instrumento de planeación estratégico y normativo para el Campus Central de la Ciudad Universitaria, coordinar, mediante un Órgano de Gestión, las políticas de actuación, programas y acciones derivadas del plan, establecer los instrumentos de colaboración necesarios para fomentar una gestión participativa y asegurar el manejo y conservación tanto de los componentes materiales como inmateriales del sitio.

\section{c) Municipio de Cuenca (Ecuador) ${ }^{4}$}

El municipio de Cuenca gestiona su patrimonio cultural material a través de la Dirección Áreas Históricas y Patrimoniales cuya visión respecto al Centro Histórico de Cuenca es visualizar su espacio como un elemento vivo, en permanente evolución, recuperado, sano, plenamente integrado a la dinámica general de la ciudad del siglo XXI, respetando su legado histórico y cultural, para alcanzar esto "desarrolla un proceso sostenido de planificación y manejo sustentable a corto, mediano y largo plazo en los ámbitos residenciales, urbano-arquitectónico-paisajístico, de equipamientos, económico, etc., que posibiliten una organización comunitaria y una convivencia humana participativa, dinámica, atractiva y segura”. Respecto a la participación ciudadana en Cuenca y sus procesos de patrimonialización, Pérez, Julia, \& Tenze, Alicia. (2018, p. 139) señalan que

Es necesario trabajar de forma unitaria con el Municipio y con el resto de instituciones públicas como el Instituto Nacional de Patrimonio Cultural (INPC), reforzado por el trabajo de investigación de la academia y con la posibilidad de que todos los interesados puedan participar, especialmente los habitantes del Centro Histórico (Pérez, Julia, \& Tenze, Alicia,2018, p.139).

\section{Conclusiones}

Las normativas nacionales y convenciones internacionales ratificadas por Chile, nos hablan de la urgencia que existe por mejorar las gestiones del patrimonio cultural con un énfasis en la gobernanza, siendo una herramienta para que las comunidades legatarias y portadoras de saberes, puedan definir qué es su patrimonio cultural y de qué forma debe ser administrado y salvaguardado. El centralismo afecta en la toma decisiones y en los tiempos que los grupos o colectividades debe esperar para que el Estado tramite declaratorias e inicie acciones de protección.

\footnotetext{
${ }^{3}$ http://www.comitedeanalisis.unam.mx/pdf/Plan-de-Gestion.pdf

${ }^{4}$ http://www.cuenca.gob.ec/?q=dahp
} 


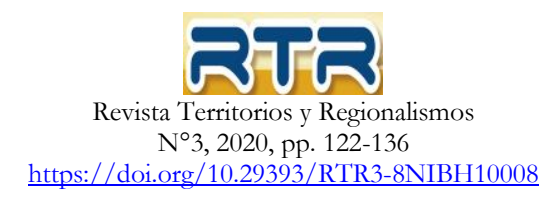

Gestionar el patrimonio cultural desde las regiones con una mirada local es uno de los desafíos con miras a la descentralización. Es por eso que daremos a conocer cuáles son las estrategias que debiese asumir el Estado y las municipalidades para atender a una necesidad cultural que, con el pasar del tiempo, se ha convertido en una exigencia por parte de la ciudadanía. Según la información levantada mediante una revisión bibliográfica y entrevistas a actores vinculados en la gestión patrimonial a nivel local, nacional e internacional, podemos señalar los siguientes desafíos:

1-Desarrollo local que fortalezca la identidad: Para lograr un trabajo exitoso en el ámbito del patrimonio cultural, es importante que las administraciones locales consideren la identidad como una línea de trabajo en su gestión y creen un espacio dentro de su orgánica institucional que se enfoque en abordar esta temática, mediante una dirección de cultura o unidad de patrimonio cultural, que visibilice las identidades locales y los patrimonios que los ciudadanos y ciudadanas consideren que deben ser protegidos o salvaguardados. Además, las municipalidades deben disponer sus normativas e instrumentos con los que cuentan para asegurar que se fortalezca la identidad de la comuna y dialoguen con las decisiones que apunten a un desarrollo mediante los Planes reguladores, Planes de desarrollo comunal, entre otros.

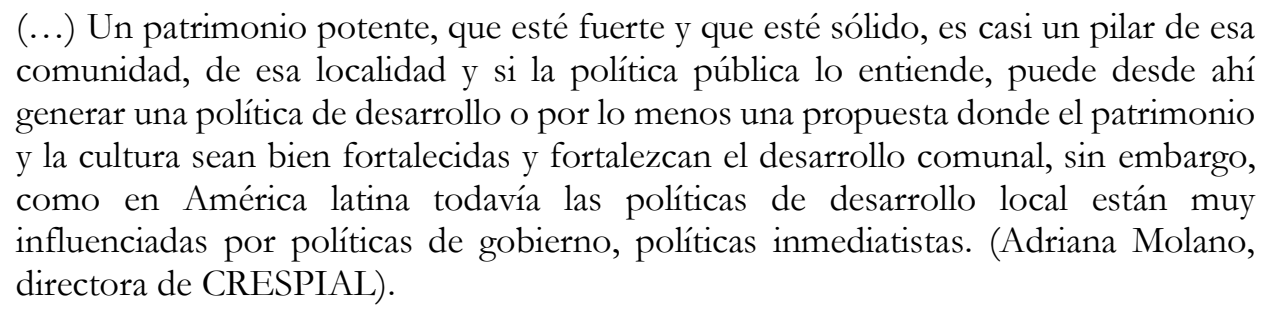

2-Fortalecimiento de capacidades de los equipos municipales: Los equipos que componen las Direcciones de cultura o Unidades de Patrimonio, deben ser multidisciplinarios para que las acciones que realicen, respondan a un análisis desde diversas visiones profesionales. Junto con ello, deben tener un conocimiento sobre las convenciones del patrimonio cultural creadas por la UNESCO, las normativas nacionales relacionadas y las políticas culturales, lo que se transforman en un paraguas a la hora de gestionar.

Tener un equipo fortalecido que tenga comprensión, no solo del marco normativo nacional o internacional, sino que también un ojo clínico para saber cómo emplazar una estrategia en relación a su coyuntura y espacio (...) siempre hay proyectos e iniciativas, pero a veces no responden a lo que deberían responder para lograr un cambio efectivo y real. (Gabriela Ugarte, Técnico CRESPIAL)

También es fundamental la capacidad de articulación de los equipos y la disposición de la autoridad para que los departamentos trabajen de manera coordinada "Los equipos de patrimonio deben tener vínculo directo con el resto del municipio, una unidad de patrimonio que conversa y que participa de los proyectos urbanos de la secretaría de planificación, que trabaja en los instrumentos de planificación de la norma urbana, que conversa con la Dirección de desarrollo comunitario, que trabaja con el equipo jurídico para poder exigir y fiscalizar". (Erwin Brevis, Secretario Técnico CMN).

3-Recursos destinados a la gestión del Patrimonio cultural: Al momento de llevar a cabo la distribución presupuestaria, se espera que existan recursos destinados a estrategias de salvaguardia, difusión, educación y protección del patrimonio cultural. Teniendo en consideración que las acciones financiadas no tendrán un efecto inmediato en la ciudadanía, sino que es una intervención a largo plazo 


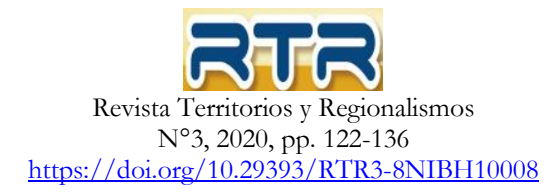

que tendrá una respuesta en las siguientes generaciones. Sin embargo, entender esta dinámica de trabajo no es fácil dentro de una institución, ya que los recursos suelen estar destinados a otras áreas.

"Los recursos no son priorizados, por ejemplo, en este contexto de pandemia, inmediatamente sabemos que cultura y con ella también patrimonio no son priorizadas. Entonces quizá un montón de recursos que, en una instancia, casi asegurados, luego han sido orientados hacia la contingencia. Así que influye mucho el tema de la de la voluntad política cuando tienen que votar los concejales y allí se van entrampado mucho, muchos procesos" (Karin Cárdenas, encargada UPA Chillán).

Adriana Molano, señala desde su experiencia en la gestión del patrimonio cultural en América latina que esta problemática está presente en gran parte de los países.

"Si hay poca plata a nivel nacional, imagínate a nivel local. En Colombia se creó una estrategia económica financiera en la que se cobra un impuesto al celular y ese impuesto va dirigido a los patrimonios de la humanidad, no sabes la dificultad de que esos gobiernos locales entendieran que esa plata fuera dirigida a esas comunidades $O$ a esos patrimonios" (Adriana Molano, directora CRESPIAL)

4-Gestión dialogante con Universidades, gobierno central y ciudadanía: Abordar el patrimonio cultural tiene una complejidad técnica, requiere de un equipo especialista que conozca sobre medidas conservación, protección y salvaguardia, puesto que, si se ejecutan acciones incorrectas se puede generar un daño irreparable en los bienes culturales. De igual manera, deben tener la capacidad de levantar de forma participativa las opiniones de la ciudadanía respecto a la gestión de su patrimonio cultural y las acciones que se diseñarán y ejecutarán. Por esta razón, es primordial que el trabajo que desarrollen los municipios sea mancomunado con los lineamientos técnicos que puede ofrecer el gobierno central, pero también con las Universidades. "Las universidades debiesen tener un rol más activo, ser policías de lo público, en qué sentido, en que debiesen estar más atentos a las políticas de patrimonio cultural" (Javier Ramírez, Unidad de Patrimonio UdeC).

Estos desafíos orientan a que las administraciones locales mejoren su forma de entender y de abordar el patrimonio cultural desde los territorios, considerando la identidad como un eje central en la gestión municipal, pensando en el legado cultural que se transmitirá a las nuevas generaciones.

Contemplar este ámbito de acción como un eje transversal dentro del rol que cumple una municipalidad con la ciudadanía, favorece el desarrollo local y el respeto por la diversidad cultural en contextos en los cuales se viven dinámicas socioculturales como la migración.

El patrimonio cultural busca valorar los saberes tradiciones artesanales, productivos, culinarios, ritos y fiestas. Pretende revitalizar las memorias colectivas y la forma en la que se concibe lo cotidiano, y la única manera de llevar a cabo acciones que estén lo más cercanas a la realidad y visión de las personas es a través de los Municipios y los equipos que los componen.

\section{BIBLIOGRAFÍA}

Bello, D., \& Valenzuela, E. (2014). Manual de Ciencia Política. Santiago de Chile: RIL editores. Bonet Gutiérrez, O. (2009). Gestión barrial en el Centro Histórico de Cusco.

Escobar, A. (1997). Antropología y desarrollo. Revista Internacional de Ciencias Sociales , 154 


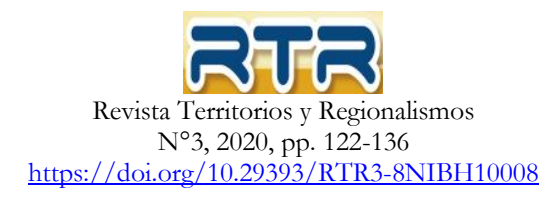

Fontal Merillas, Olaia. (2016). Educación patrimonial: retrospectiva y prospectivas para la próxima década. Estudios pedagógicos (V aldivia), 42(2), 415-436. https://dx.doi.org/10.4067/S0718$\underline{07052016000200024}$

García Canclini , N. (1999). Los usos sociales del Patrimonio Cultural. Izlapalapa, México: Departamento de Antropología de la UAM.

Henríquez, O., \& Valenzuela, E. (2019). La política territorial en países unitarios de la Zona Andina: mutabilidad y brecha del régimen subnacional. Revista del CLAD Reforma y Democracia, 75, 139-174.

http://old.clad.org/portal/publicaciones-del-clad/revista-clad-reformademocracia/articulos/075-octubre-2019/05\%20Henriquez $\% 20 \mathrm{y} \% 20$ Valenzuela.pdf

Ministerio de Educación (1970). Ley $\mathrm{N}^{\circ} 17.288$ que legisla sobre monumentos nacionales. Disponible en: https://www.bcn.cl/leychile/navegar?idNorma $=28892$

Ministerio de Educación (2017). Ley 21.045 Crea el Ministerio de las Culturas, las Artes y el Patrimonio. Disponible en: https://www.bcn.cl/leychile/navegar?idNorma=1110097

Ministerio de Relaciones Exteriores (1980). Decreto $N^{\circ} 259$ que promulga la convención sobre la protección del patrimonio mundial, cultural y natural, suscrita en UNESCO, Paris, el 16 de noviembre de 1972. Disponible en: https://www.bcn.cl/leychile/navegar?idNorma=265641

Montecinos, Egon. (2006). Descentralización y democracia en Chile: Análisis sobre la participación ciudadana en el presupuesto participativo y el plan de desarrollo comunal. Revista de ciencia politica (Santiago), 26(2), 191-208. https://dx.doi.org/10.4067/S0718-090X2006000200011

Perafán, C., \& Pabón, M. (1998). Los modelos de adaptación y culpabilidad. El concepto de desarrollo en la región de la sierra nevada de Santa

Pérez, Julia, \& Tenze, Alicia. (2018). La participación ciudadana en la Gestión del Patrimonio Urbano de la ciudad de Cuenca (Ecuador). Estoa. Revista de la Facultad de Arquitectura y Urbanismo de la Universidad de Cuenca, 7(Supl. 14), 229-254. https://dx.doi.org/10.18537/est.v007.n014.a10

Santa-Cruz, Juan Carlos. (2018). Gestión del patrimonio carbonífero en contextos recesivos: del sitio aislado a la cuenca minera. Una reflexión a partir de las experiencias de las cuencas ConcepciónArauco en Chile y Nord-Pas de Calais en Francia. EURE (Santiago), 44(132), 265289. https://dx.doi.org/10.4067/s0250-71612018000200265

UNESCO (1972). Convención sobre la Protección del Patrimonio Mundial, Cultural y Natural, Paris. Disponible en: https://unesdoc.unesco.org/ark:/48223/pf0000114044.page=134

UNESCO (2003). Convención para la salvaguarda del patrimonio cultural inmaterial, Paris. Disponible en: https://unesdoc.unesco.org/ark:/48223/pf0000132540 spa

Zamora, E. (2011). Sobre patrimonio y desarrollo. Aproximación al concepto de patrimonio cultural y su utilización en procesos de desarrollo territorial. Pasos. Revista de Turismo y Patrimonio Cultural, 101-111. 